\title{
LIPIDS OF CULTIVATED AND WILD VACCINIUM SPP. BERRIES FROM LATVIA
}

\author{
Linards Klavins $^{1 *}$, Arturs Viksna ${ }^{2}$, Jorens Kviesis ${ }^{1}$, Maris Klavins ${ }^{1}$ \\ ${ }^{1}$ Laboratory of Natural Products Research, University of Latvia, Raina blvd. 19, Riga, Latvia, e-mail: linards.klavins@lu.lv \\ ${ }^{2}$ Faculty of Chemistry, University of Latvia, Raina blvd. 19, Riga, Latvia
}

\begin{abstract}
Production, consumption and processing of different berries nowadays is increasing, considering taste properties and health benefits of these berries. In Northern countries and Latvia of special importance are berries belonging to Vaccinium species (cranberries, bilberries, blueberries, lingonberries and others) and many of these berries are considered as the super fruits. Value of the berries is determined by the presence of many biologically active and valuable substances and amongst them berry lipids have a special role. Lipids of Vaccinium berries include not only triglycerides, but also fatty acids, alcohols, triterpenes (sterols), terpenes and other substances The aim of the present study was to investigate and compare the composition of lipids in five Vaccinium spp. berries and of eight Vaccinium corymbosum varieties. Lipid composition was analysed using gas chromatography with mass spectrometric detection. The lipid fraction contained compound classes like fatty acids, sterols, triterpenoids, alkanes, phenolic and carboxylic acids and tocopherols. All fresh

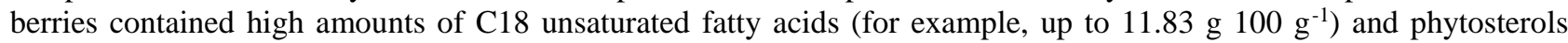
(10.97 $\mathrm{g}$ of $\beta$-sitosterol $100 \mathrm{~g}^{-1}$ of blueberry lipid extract ), and high amounts of benzoic acid were found in lingonberries

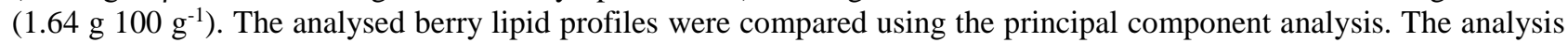
showed that the lipid profiles of the studied berries reflect their taxonomy-separate species could be distinguished from one another. Considering the composition of berry lipids, they can find wide application at development of functional food.
\end{abstract}

Keywords: lipids, waxes, Vaccinium berries, GC-MS

\section{Introduction}

Wild and locally cultivated berries are becoming more popular considering the taste properties, health benefits and growing demand in healthy foods. In Northern countries the most used berries are strawberries and berries belonging to Vaccinium species. Vaccinium berries - bog bilberry (Vaccinium uliginosum L.), bilberry (Vaccinium myrtillus L.), American cranberry (Vaccinium macrocarpon), lingonberry (Vaccinium vitis-idaea $\mathrm{L}$.), cranberry (Vaccinium oxycoccus L.) and blueberries (Vaccinium corymbosum L.) are sampled in forests and bogs, but American cranberries and highbush blueberries are widely cultivated. Vaccinium berries are rich source of polyphenolic substances, carbohydrates, vitamins as well as lipids (Arevström et al., 2019; Klavins et al., 2015). Highbush blueberries and American cranberries are commercially important as they have large fruits, long shelf life, excellent taste properties and considering this, many cultivars are developed and their cultivation takes place worldwide, the cultivation amounts are steadily increasing (Krueger et al., 2013). Vaccinium corymbosum berries can be considered as functional food and many cultivars are developed differing in taste, size and colour of berries, productivity and length of growing season (Kim et al., 2013).

Vaccinium berry phenolic compounds are responsible for their high radical scavenging capacity and beneficial effects on human health (Nile, Park, 2014). Another important group of substances in the composition of Vaccinium berries are their lipids (Klavins et al., 2016). Berry lipids are berry skin waxes, seed lipids and cytoplasm lipids. By the chemical composition
Vaccinium berry lipids include triglycerides, fatty acids, alcohols, alkanes as well as sterols, terpenes and other groups of substances (Dulf et al., 2012). Extraction of berry lipids is usually done using low-polarity organic solvents, for example, chloroform, hexane, petroleum ether. Combining the solvent with various extraction methods is advisable to achieve high extraction yields, such methods include Soxhlet, maceration, ultrasound assisted extraction (Wang, Weller, 2006). The composition of berries depends on their vegetation locations and thus it is important to study berry composition in each specific site. A further important aspect is to identify the most health beneficial species from naturally grown as well as many commercially available Vaccinium berry species, for example, Vaccinium corymbosum.

The aim of the present study was to investigate and compare the composition of lipids in five Vaccinium spp. berries of which eight were Vaccinium corymbosum varieties.

\section{Materials and Methods \\ Plant materials}

In this study, six berry species were examined for their lipid composition. The examined wild berries were bog bilberry (Vaccinium uliginosum L.), bilberry (Vaccinium myrtillus L.), American cranberry (Vaccinium macrocarpon), lingonberry (Vaccinium vitis-idaea $\mathrm{L}$.), cranberry (Vaccinium oxycoccus $\mathrm{L}$.) and eight varieties of cultivated blueberry (Vaccinium corymbosum L.), namely, 'Blue Crop', 'Blue Gold', 'Chandler', 'Chippewa', 'Duke', 'North Blue', 'Patriot', 'Polaris'. 
The different blueberry varieties and American cranberries were harvested at a commercial blueberry farm Z/S "Strelnieki" located on the outskirts of town Jurmala, Latvia. Bog bilberries, bilberries, cranberries and lingonberries were harvested from the forests belonging to Kemeru National Park. To avoid contamination and possible damage to the berries, they were harvested into glass containers previously washed with chloroform ( $\geq 99 \%$, Sigma Aldrich). In total, approximately $500 \mathrm{~g}$ of berries were harvested for each sample, all berries were harvested during the summer / autumn of 2018. After the harvest, berries were placed into a refrigerated sample box and delivered to the laboratory, where they were dried at $40{ }^{\circ} \mathrm{C}$ in a drying oven (Memmert, Germany) and afterwards used for the extraction. Temperature of $40{ }^{\circ} \mathrm{C}$ was chosen to avoid degradation of substances in the berries.

\section{Extraction of berry lipids}

Extraction was performed based on the previous work (Klavins et al., 2015). In short, 5.00 $\pm 0.01 \mathrm{~g}$ of dried berries were weighed into a $100 \mathrm{~mL}$ glass extraction vessel. $50 \mathrm{~mL}$ of chloroform was added to the extraction vessel, which was placed into the ultrasound bath (Cole-Parmer) for 20 minutes. After the ultrasound assisted extraction the sample was removed and filtered through a $10 \mu \mathrm{m}$ filter paper to remove the solids. The used filter paper was then placed back into the extraction vessel and $50 \mathrm{~mL}$ of chloroform were added. The extraction was repeated three times. All the extracts were combined and placed into a round-bottom flask for evaporation. Chloroform was evaporated using Rota-Vap ${ }^{\circledR}$ rotary evaporator until approximately $5 \mathrm{~mL}$ of extract was left in the flask. The extract was placed into a glass tube and the flask was washed three times with $2 \mathrm{~mL}$ chloroform to remove any residual extract. Samples were stored at $-20{ }^{\circ} \mathrm{C}$ until the analysis. Extraction and analysis were carried out in triplicate.

\section{GC-MS analysis}

Berry lipid-chloroform extracts were evaporated under a flow of nitrogen. Silylation was done using N,O-bis (trimethylsilyl) trifluoroacetamide, BSTFA $(200 \mu \mathrm{L}$, Sigma-Aldrich) in pyridine $(1300 \mu \mathrm{L}$, Sigma-Aldrich), for 1 hour at $60^{\circ} \mathrm{C}$. GC-MS analysis was performed using GC-2010 plus coupled with GC/MS QP-2010 Ultra mass detector (Shimadzu, Japan). The column used was Restek Rxi®-5MS (30 m×0.25 mm×0.25 $\mu \mathrm{m}$; Crossbond $® 5 \%$ diphenyl+95\% dimethyl polysiloxane, Restek USA) with working temperature range 40 to $350{ }^{\circ} \mathrm{C}$. He (Helium) was used as a carrier gas with a total flow rate of $10.8 \mathrm{~mL} \mathrm{~min}^{-1}$ and column flow rate of $0.71 \mathrm{~mL} \mathrm{~min}^{-1}$. The split ratio was 1:10 and injection temperature $290{ }^{\circ} \mathrm{C}$. The temperature programme used was: oven temperature $200{ }^{\circ} \mathrm{C}(2 \mathrm{~min})$ increased to $250{ }^{\circ} \mathrm{C}$ at the rate of $30{ }^{\circ} \mathrm{C} \mathrm{min}^{-1}$ and held for 7 min then increased to $310{ }^{\circ} \mathrm{C}$ at the rate of $10{ }^{\circ} \mathrm{C} \mathrm{min}-1$ and kept for $14 \mathrm{~min}$. Injection of $1.0 \mu \mathrm{L}$ sample was performed using an autosampler. Mass selective detector with quadrupole mass analyser was used with electron impact (EI) ionisation, ionization voltage of $70 \mathrm{eV}$. The ion source temperature was $230{ }^{\circ} \mathrm{C}$ and interface temperature $290{ }^{\circ} \mathrm{C}$. Identification of the compounds separated in the GC was performed using Shimadzu LabSolutions 4.30 software, coupled with NIST'14 spectral library.

Quantification was done by preparing standard solutions of heptadecanoate $(\geq 99.0 \%)$, 1-dodecanal $(\geq 98.0 \%)$, $( \pm)$ - $\alpha$-tocopherol (99\%), 1-octadecanol (99\%), and n-tetracosane ( $\geq 99.5 \%$ ) (Sigma Aldrich, Germany) in the concentration range $1.5-500 \mu \mathrm{g} \mathrm{mL}^{-1}$.

\section{Data analysis}

Principal component analysis (PCA) on correlation matrix was performed to evaluate relationship among various tested berries. Error bars in the Figures represent 95\% confidence interval. Statistical analysis and data visualisation was done using SAS JMP®, Version 13 (SAS Institute Inc., Cary, NC, USA).

\section{Results and Discussion}

Studied Vaccinium berries in general have relatively similar lipid concentrations extracted from whole, dried berries with chloroform, ranging from 6.90 to

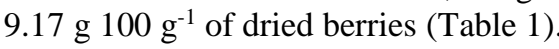

Table 1

Lipid concentrations in studied Vaccinium berry species

\begin{tabular}{|c|c|c|}
\hline Berries & $\begin{array}{l}\text { Lipid extract, } \\
\text { g } 100 \mathrm{~g}^{-1} \text { dried } \\
\text { berries }\end{array}$ & $\begin{array}{l}\text { Total identified } \\
\text { lipids, } \mathrm{g} 100 \mathrm{~g}^{-1} \\
\text { of lipid extract }\end{array}$ \\
\hline $\begin{array}{l}\text { American } \\
\text { cranberry }\end{array}$ & 9.17 & 39.62 \\
\hline Bilberry & 8.37 & 33.46 \\
\hline Lingonberry & 9.05 & 55.24 \\
\hline Bog cranberry & 7.57 & 49.35 \\
\hline Bog bilberry & 8.66 & 53.18 \\
\hline $\begin{array}{l}\text { Blueberry cv. } \\
\text { Blue crop }\end{array}$ & 6.90 & 52.28 \\
\hline $\begin{array}{l}\text { Blueberry } \\
\text { cv. Blue gold }\end{array}$ & 7.84 & 50.95 \\
\hline $\begin{array}{l}\text { Blueberry } \\
\text { cv. Blue ray }\end{array}$ & 7.10 & 70.04 \\
\hline $\begin{array}{l}\text { Blueberry } \\
\text { cv. Chippewa }\end{array}$ & 7.51 & 83.82 \\
\hline $\begin{array}{l}\text { Blueberry } \\
\text { cv. Duke }\end{array}$ & 8.15 & 53.40 \\
\hline $\begin{array}{l}\text { Blueberry } \\
\text { cv. North blue }\end{array}$ & 8.18 & 69.22 \\
\hline $\begin{array}{l}\text { Blueberry } \\
\text { cv. Patriot }\end{array}$ & 7.65 & 62.48 \\
\hline $\begin{array}{l}\text { Blueberry } \\
\text { cv. Polaris }\end{array}$ & 7.46 & 44.39 \\
\hline
\end{tabular}

Lipid concentrations in wild Vaccinium berries and American cranberries were slightly higher than in varieties of blueberries. Relatively similar concentrations of lipids in Vaccinium berries might be related to similar and species-independent functions in berries (Yang, Kallio, 2002), such as protective properties of berry wax layer as well as functional lipids 
participating in the regulatory processes of plant development during their growth and maturing (Yang, Kallio, 2002) as well as present in the berry seeds. Analysis of studied berry lipids were done using gas chromatography coupled with mass spectrometric detection of samples derivatized with trimethylsilygroups and a large number of substances were found. The substances were identified by the retention index and mass spectra, and compared with the NIST mass spectral library data (Fig. 1). The mass spectra were matched with at least $90 \%$ confidence. Nevertheless, the total amount of identified substances in the extracts ranged from $33.46 \%$ to $83.82 \%$ in the studied berries.

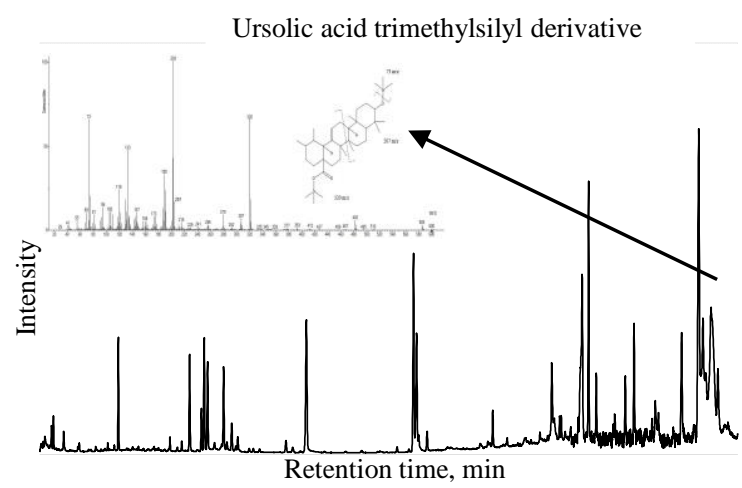

Figure 1. A typical GC/MS chromatogram of berry lipid extract (blueberry variety 'Polaris)' and an example of ursolic acid TMS derivative mass spectrum

The unidentified portion of the extracts (Table 1) are believed to be complex compounds with large molar mass, for instance, triterpenes bound with fatty acids (Esche et al., 2012). Chromatographic runs had high repeatability, and the standard deviations between three parallel runs for the specific apparatus were less than 5-8\%. In total, approximately 120 different compounds were found as part of the berry lipids from various berries.
The identified compounds of berry lipids can be divided into 6 classes of organic substances (Fig. 2). The largest class in each berry species was fatty acids (up to $60 \%$ of the total lipids in the varieties of blueberry).

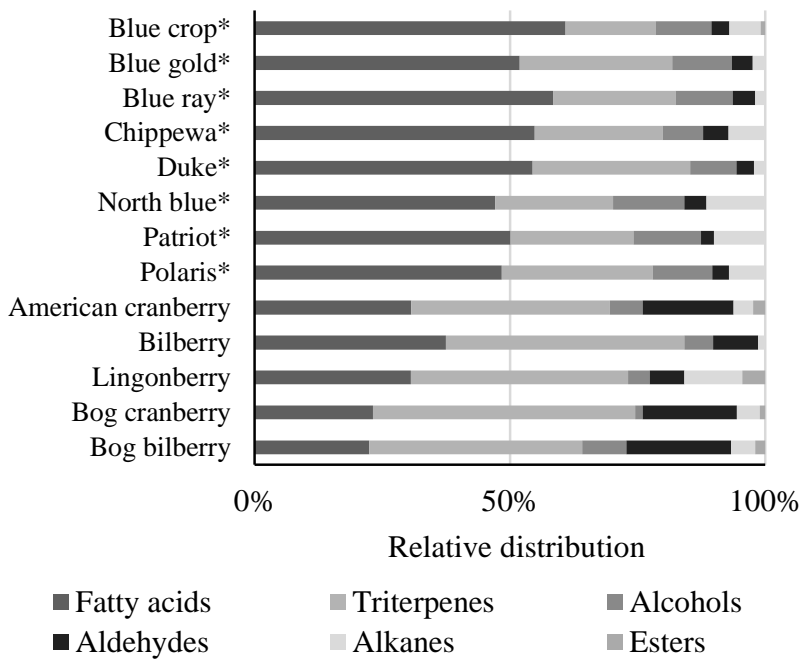

Figure 2. Relative abundance of identified compound groups as part of the studied berry lipids Berries marked with * are cultivars of Vaccinium corymbosum.

Blueberry cultivars have relatively similar profiles of compound classes (Fig. 2), which on the other hand differ from other Vaccinium berries. At the same time remarkable are high concentrations of triterpenes in composition of bilberry and other wild berries. The high content of fatty acids in the berries is due to large quantity of seeds, in which energy is stored in the form of fatty acids (Johansson, Kallio, 1997; Parry et al. 2005). Blueberry, bilberry and both cultivars of highbush blueberries (cv. Blue Ray and cv. Chippewa) are closely related, which can also be seen in their compound class profiles. In the research of Parry et al. (2005) blueberry seed oils were analysed, the fatty acid contents shown were similar to that of reported in this study.

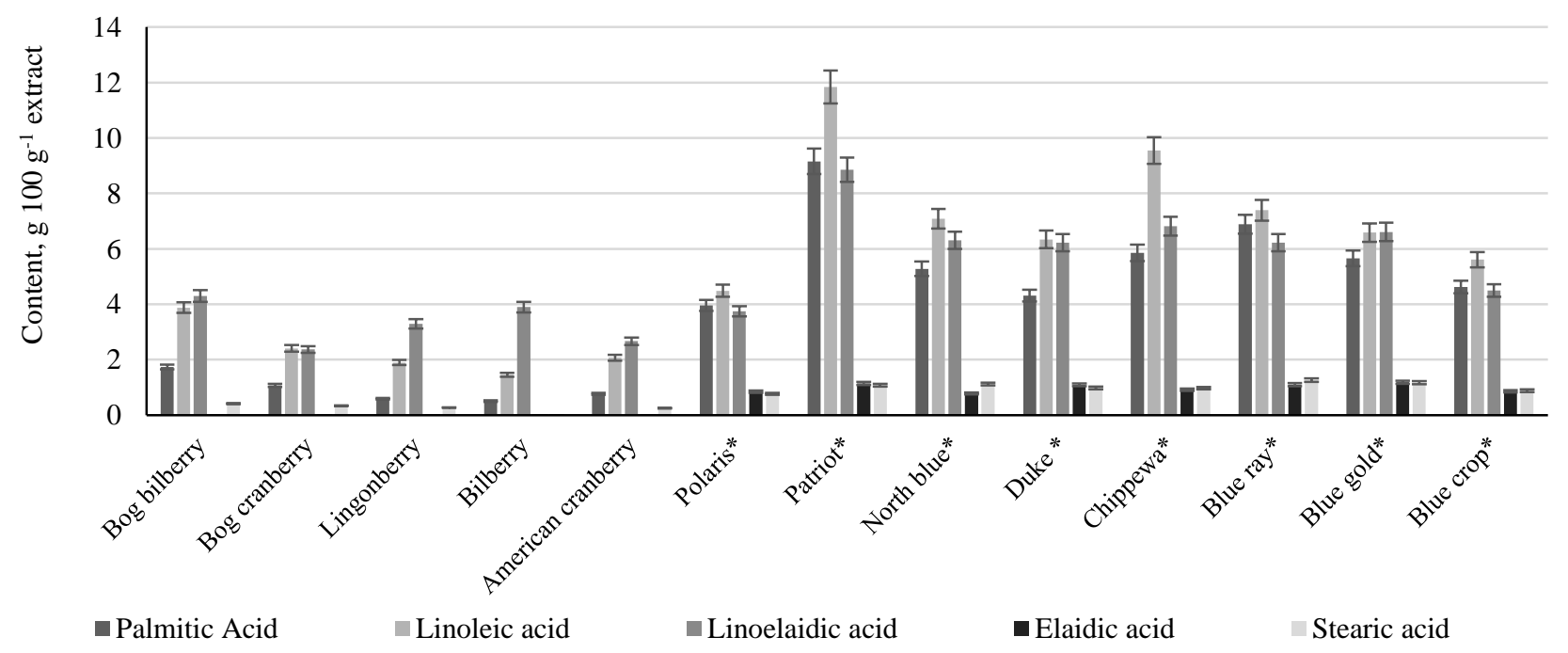

Figure 3. Fatty acid (C16 and C18) content in the studied berry lipids

Berries marked with * are cultivars of Vaccinium corymbosum. 
Concentration and chain length of detected alkanes in studied wild berries and cultivated berries (g of substance $100 \mathrm{~g}^{-1}$ extract)

\begin{tabular}{|c|c|c|c|c|c|c|c|c|}
\hline \multirow{2}{*}{ Berries } & \multicolumn{8}{|c|}{ Alkanes } \\
\hline & C19 & $\mathrm{C23}$ & $\mathrm{C25}$ & $\mathrm{C26}$ & $\mathrm{C28}$ & C29 & C30 & C31 \\
\hline Bog bilberry & $<$ LOD & 0.13 & 0.38 & $<$ LOD & 3.31 & 0.9 & $<\mathrm{LOD}$ & $<\mathrm{LOD}$ \\
\hline Bog cranberry & $<\mathrm{LOD}$ & $<\mathrm{LOD}$ & $<\mathrm{LOD}$ & $<\mathrm{LOD}$ & 1.53 & 1.49 & $<\mathrm{LOD}$ & $<\mathrm{LOD}$ \\
\hline Lingonberry & $<\mathrm{LOD}$ & $<\mathrm{LOD}$ & 0.13 & $<\mathrm{LOD}$ & 0.11 & 6.81 & 0.42 & 1.67 \\
\hline Bilberry & $<\mathrm{LOD}$ & $<\mathrm{LOD}$ & 0.21 & $<\mathrm{LOD}$ & $<\mathrm{LOD}$ & 0.34 & $<\mathrm{LOD}$ & $<\mathrm{LOD}$ \\
\hline American cranberry & $<\mathrm{LOD}$ & $<\mathrm{LOD}$ & $<\mathrm{LOD}$ & $<\mathrm{LOD}$ & $<\mathrm{LOD}$ & 2.33 & $<\mathrm{LOD}$ & $<\mathrm{LOD}$ \\
\hline Blueberry cv. Polaris & $<\mathrm{LOD}$ & $<\mathrm{LOD}$ & 0.22 & $<\mathrm{LOD}$ & 0.25 & 4.58 & $<\mathrm{LOD}$ & 0.73 \\
\hline Blueberry cv. Patriot & 0.33 & $<\mathrm{LOD}$ & 0.36 & $<\mathrm{LOD}$ & 0.45 & 8.01 & $<\mathrm{LOD}$ & 2.70 \\
\hline Blueberry cv. North blue & 0.28 & 0.24 & 0.33 & 0.25 & 0.66 & 9.33 & 0.56 & 2.80 \\
\hline Blueberry cv. Duke & 0.22 & $<\mathrm{LOD}$ & 0.20 & 0.20 & $<\mathrm{LOD}$ & 0.97 & $<\mathrm{LOD}$ & 0.22 \\
\hline Blueberry cv. Chippewa & 0.19 & $<\mathrm{LOD}$ & 0.62 & 0.44 & 0.38 & 6.05 & 0.29 & 0.91 \\
\hline Blueberry cv. Blue ray & 0.30 & $<\mathrm{LOD}$ & 0.27 & $<\mathrm{LOD}$ & 0.34 & 1.31 & $<\mathrm{LOD}$ & $<\mathrm{LOD}$ \\
\hline Blueberry cv. Blue gold & 0.29 & $<\mathrm{LOD}$ & 0.22 & $<\mathrm{LOD}$ & 0.15 & 1.03 & $<\mathrm{LOD}$ & 0.24 \\
\hline Blueberry cv. Blue crop & 0.24 & $<\mathrm{LOD}$ & 0.24 & 0.21 & 0.25 & 3.18 & $<\mathrm{LOD}$ & 0.89 \\
\hline
\end{tabular}

LOD - amount lower than the limit of detection $\left(0.01-0.2 \mu \mathrm{g} \mathrm{g}^{-1}\right)$

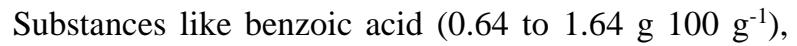

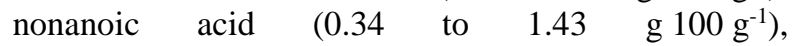
$m$-hydroxybenzoic acid $\left(0.16\right.$ to $\left.0.52 \mathrm{~g} 100 \mathrm{~g}^{-1}\right)$,

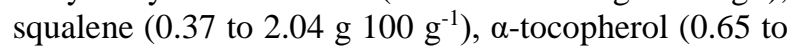

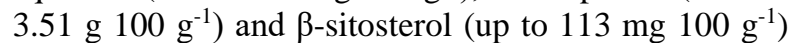
were found in all of the studied oils obtained from berries. The substance with the highest concentration

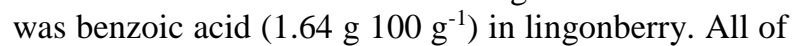
the $\mathrm{C} 18$ unsaturated fatty acids were also found in high

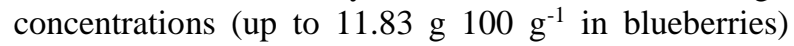
(Fig. 3). Looking deeper in the profile of long-chain fatty acids in Vaccinium berries (Fig. 3) differences amongst the studied berries are more evident $(\mathrm{p}<0.001)$, the studied blueberry varieties have a higher fatty acid content than the wild berries (Fig. 3). Cultivars of Vaccinium corymbosum have up to $12.02 \mathrm{~g}$ of linoleic acid per $100 \mathrm{~g}$ of berry extract, while the average for



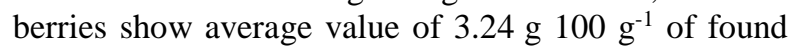
fatty acids (Fig. 3).

In the research of Parry et al. (2005) blueberry seed oils were analysed, the fatty acid contents shown were similar to that of reported in this study, however, triterpene contents were not reported. Also, the used blueberry variety was not mentioned (Parry et al., 2005), which can be an important factor and have influence on the obtained result, as the obtained lipid profiles shown in the present research suggest (Figure 2). A group of substance often found as a part of lipid extracts are alkanes. These compounds are a part of berry epicuticular wax and in cytoplasm of berry they are for biosynthesis of other plant metabolites. The carbon chain length of alkanes found in berries ranges from C19 to C31 (Table 2).

As the most prominent of the alkanes in berries the $\mathrm{C} 29$ alkane (nonacosane) was found (Fig. 4). Among the studied wild berries, the highest concentration of nonacosane was found in lingonberry $\left(6.81{\left.\mathrm{~g} 100 \mathrm{~g}^{-1}\right)}^{-1}\right.$ (Table 2). The wild bilberries and bog bilberries had low alkane concentrations, and in bilberry, only C25 and C29 alkanes were found. The studied blueberry varieties showed a much wider alkane content, for example, blueberry variety 'North blue' contained 8 different alkanes (Table 2), with the most prominent alkane being nonacosane (Fig. 4). Alkanes have also been reported as part of blueberry cuticular wax, where alkanes are responsible for hydrophobicity of berry surface (Chu et al., 2017). The most abundant triterpene was found to be ursolic acid, followed by beta-sitosterol and betaamyrin. In the wild berries like bog bilberry and bog cranberry 27.06 and $28.23 \mathrm{~g}$ of ursolic acid in $100 \mathrm{~g}^{-1}$ extract were found, respectively. $\beta$-sitosterol was found in high concentrations in two blueberry cultivars $10.72 \mathrm{~g}$ per $100 \mathrm{~g}^{-1}$ in 'Patriot' and $10.97 \mathrm{~g}$ per $100 \mathrm{~g}^{-1}$ in 'Chippewa' (Table 3).

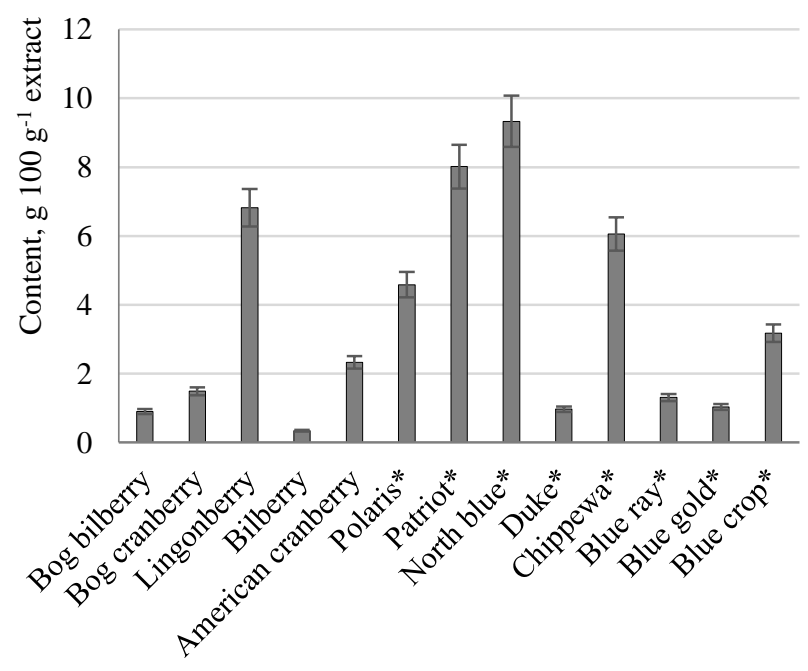

Figure 4. Concentration of nonacosane (C29) in the studied berries

Berries marked with * are cultivars of Vaccinium corymbosum.

Triterpenes like lupeol was found in only 2 berries, 'North blue' and 'Blue ray'. Overall, the concentration of triterpenoids was found to be higher in the wild berries. 
Concentration of triterpenes found in the studied berries ( $\mathrm{g}$ of substance $100 \mathrm{~g}^{-1}$ extract)

\begin{tabular}{|c|c|c|c|c|c|}
\hline Berry & Ursolic acid & $\beta$-sitosterol & $\beta$-amyrin & $\alpha$-amyrin & lupeol \\
\hline Bog bilberry & 27.06 & 6.35 & 0.48 & 0.48 & $<\mathrm{LOD}$ \\
\hline Bog cranberry & 28.23 & 4.61 & $<\mathrm{LOD}$ & 0.78 & $<\mathrm{LOD}$ \\
\hline Lingonberry & 24.40 & 6.03 & 1.76 & 1.4 & $<\mathrm{LOD}$ \\
\hline Bilberry & 12.75 & 4.56 & 1.52 & $<\mathrm{LOD}$ & $<\mathrm{LOD}$ \\
\hline American cranberry & 17.08 & 5.56 & 0.92 & $<\mathrm{LOD}$ & $<\mathrm{LOD}$ \\
\hline Blueberry cv. Polaris & 12.37 & 8.66 & 2.68 & $<\mathrm{LOD}$ & $<\mathrm{LOD}$ \\
\hline Blueberry cv. Patriot & 17.18 & 10.72 & $<\mathrm{LOD}$ & $<\mathrm{LOD}$ & $<\mathrm{LOD}$ \\
\hline Blueberry cv. North blue & 10.73 & 11.30 & 3.40 & 0.76 & 2.01 \\
\hline Blueberry cv. Duke & 12.39 & 9.77 & 2.46 & $<$ LOD & $<\mathrm{LOD}$ \\
\hline Blueberry cv. Chippewa & 8.75 & 10.97 & 10.66 & $<\mathrm{LOD}$ & $<\mathrm{LOD}$ \\
\hline Blueberry cv. Blue ray & 12.87 & 9.96 & 1.34 & $<\mathrm{LOD}$ & 2.07 \\
\hline Blueberry cv. Blue gold & 10.36 & 9.88 & 0.94 & 1.84 & $<\mathrm{LOD}$ \\
\hline Blueberry cv. Blue crop & 4.47 & 9.49 & $<\mathrm{LOD}$ & $<\mathrm{LOD}$ & $<\mathrm{LOD}$ \\
\hline
\end{tabular}

LOD - amount lower than the limit of detection $\left(0.01-0.2 \mu \mathrm{g} \mathrm{g}^{-1}\right)$

As triterpenes have a protective function in plant-pathogen interaction, it can be assumed that the high triterpene concentration in the wild berries is due to the need of regulation and protection against various biotic and abiotic stresses (Du Fall and Solomon, 2011). Plant sterols have potential use in foodstuffs, and cosmetics (Kritchevsky and Chen, 2005)

An important group of compounds found as a part of berry lipids are triterpenes (sterols). These compounds have an important role in the plant metabolism as regulators of the cell processes. Triterpenes were found to compose $50 \%$ of identified lipids in bog cranberry and as low as $17 \%$ in blueberry variety 'Blue crop' (Fig. 2). The composition of lipids found in the studied berries was believed to be species dependent, to demonstrate this a principal component analysis (PCA) was performed. The first two components of the PCA explain $85.9 \%$ of data variability (Fig. 5).

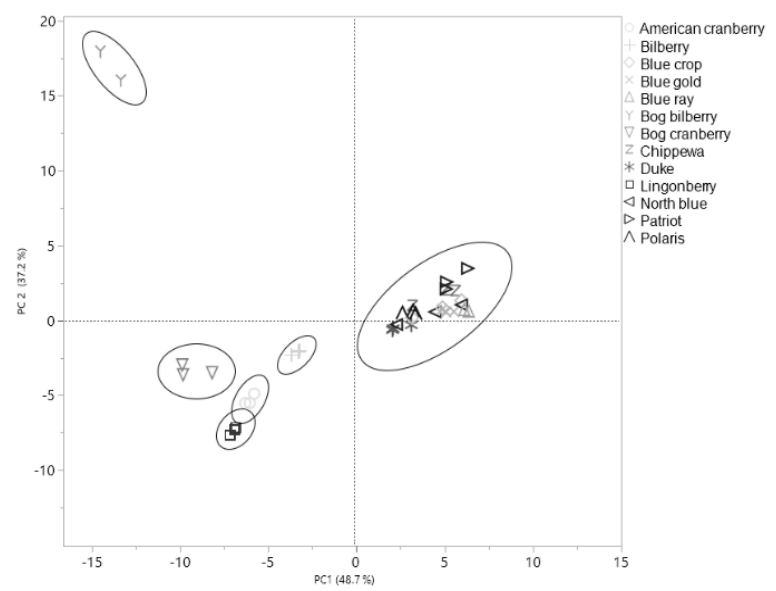

Figure 5. Principal components analysis of various berry species based on their lipid profiles

Obtained lipid profiles when subject to multivariate analysis show distinct differences among the studied berries. Bog bilberries, American cranberries, lingonberries, bog cranberries and bilberries each form a separate cluster, while all of the studied blueberry varieties form one cluster. As the blueberry data was dispersed within the $95 \%$ confidence ellipse, it could mean that differences within the same species could be distinguished. Methods like DNA fingerprinting are suggested for differentiation between berry species, however, these methods are time consuming and require specific equipment and materials as well as skilled operators (Polashock, Vorsa, 1996). Analysis of berry lipid profiles can be suggested as a cheaper, userfriendly method for authenticity testing of berry material where DNA is no longer intact. Concerning the methods of authenticity testing of berry material, stable isotope analysis can be suggested, however, using this method the specific species could not be distinguished, only the origin of the tested material (Bertoldi et al., 2019). Cranberries and lingonberries are red berries with similar appearance, using the proposed method of lipid profile analysis they can be distinguished (Fig. 5), a more comprehensive approach to chemotaxonomy is proposed by Hurkova et al. (2019) where complex metabolomics analysis is performed.

\section{Conclusions}

Vaccinium genus berries - bog bilberry, bilberry, American cranberry, lingonberry, cranberry and different varieties of blueberries have a rich composition of lipids belonging to compound classes like fatty acids (among which omega-fatty acids), sterols, triterpenoids, alkanes, phenolic acids and tocopherols. In the highest concentrations $\mathrm{C} 18$ unsaturated fatty acids and triterpenes like ursolic acid and $\beta$-sitosterol were found. Lipid concentration and composition of studied Vaccinium berries is species specific and can be used for authenticity testing of berry processing products as well as the berry material itself. Considering the rich composition of berry lipids, they can have wide application and potential for development of innovative functional foods and cosmetics.

\section{Acknowledgment}

Work of J.Kviesis and M.Klavins was supported by the European Regional Development Fund under the project No. 1.1.1.1/16/A/047 "Genus Vaccinium berry processing using 'green' technologies and innovative, 
pharmacologically characterized biopharmaceutical products". Work of L. Klavins was supported by the patron "Mikrotikls" Ltd. administered by the Foundation of University of Latvia.

\section{References}

1. Arevström L., Bergh C., Landberg R., Wu H., RodriguezMateos A., Waldenborg M. M., Magnuson A., Blanc S., Fröbert O. (2019) Freeze-dried bilberry (Vaccinium myrtillus) dietary supplement improves walking distance and lipids after myocardial infarction: an open-label randomized clinical trial. Nutrition Research, Vol. 62, p. 13-22.

2. Bertoldi D., Cossignani L., Blasi F., Perini M., Barbero A., Pianezze S., Montesano D. (2019) Characterisation and geographical traceability of Italian goji berries. Food Chemistry, Vol. 275, p. 585-593.

3. Chu W., Gao H., Cao S., Fang X., Chen H., Xiao S. (2017) Composition and morphology of cuticular wax in blueberry (Vaccinium spp.) fruits. Food Chemistry, Vol. 219, p. 436-442.

4. Du Fall L. A., Solomon P. S. (2011) Role of cereal secondary metabolites involved in mediating the outcome of plant-pathogen interactions. Metabolites, Vol. 1 (1), p. 64-78.

5. Dulf F.V., Andrei S., Bunea A., Socaciu C. (2012) Fatty acids and phytosterol contents of some Romanian wild and cultivated berry pomaces, Chemical Papers, Vol. 66 (10), p. $925-934$.

6. Esche R., Barnsteiner A., Scholz B., Engel K. H. (2012) Simultaneous analysis of free phytosterols / phytostanols and intact phytosteryl / phytostanyl fatty acid and phenolic acid esters in cereals. Journal of Agricultural and Food Chemistry, Vol. 60 (21), p. 5330-5339.

7. Hurkova K., Uttl L., Rubert J., Navratilova K., Kocourek V., Stranska-Zachariasova M., Paprstein F., Hajslova J. (2019) Cranberries versus lingonberries: A challenging authentication of similar Vaccinium fruit. Food Chemistry, Vol. 284, p. 162-170.

8. Johansson A., Kallio H. (1997) Characterization of seed oils of wild, edible Finnish berries. Zeitschrift für
Lebensmitteluntersuchung und Forschung A, Vol. 204 (4), p. 300-307.

9. Kim J. G., Kim H. L., Kim S. J., Park K. S. (2013) Fruit quality, anthocyanin and total phenolics contents, and antioxidant activities of 45 blueberry cultivars grown in Suwon, Korea, Journal of Zhejiang University Science, Vol. 14, p. 793-799.

10. Klavins L., Klavina L., Huna A., Klavins M. (2015) Polyphenols, carbohydrates and lipids in berries of Vaccinium species, Environmental and Experimental Biology, Vol. 13, p. 147-158.

11. Klavins L., Kviesis J., Steinberga I., Klavina L., Klavins M. (2016) Gas chromatography-mass spectrometry study of lipids in northern berries, Agronomy Research, Vol. 14, p. 1328-1346.

12. Krueger C. G., Reed J. D., Feliciano R. P., Howell A. B. (2013) Quantifying and characterizing proanthocyanidins in cranberries in relation to urinary tract health. Analytical Bioanalytical Chemistry, Vol. 405, p. 4385-4395.

13. Kritchevsky D., Chen S. C. (2005) Phytosterols - health benefits and potential concerns: A review. Nutrition Research, Vol. 25 (5), p. 413-428.

14. Nile S. H., Park S. W. (2014) Edible berries: Bioactive components and their effect on human health. Nutrition, Vol. 30 (2), p. 134-144.

15. Parry J., Su L., Luther M., Zhou K., Yurawecz M. P., Whittaker P., Yu L. (2005) Fatty acid composition and antioxidant properties of cold-pressed marionberry, boysenberry, red raspberry, and blueberry seed oils. Journal of Agricultural and Food Chemistry, Vol. 53 (3), p. 566-573.

16. Polashock J. J., Vorsa N. (1996) Evaluation of fingerprinting techniques for differentiation of cranberry and blueberry varieties. VI International Symposium on Vaccinium Culture, Vol. 446, p. 239-242.

17. Wang L., Weller C. L. (2006) Recent advances in extraction of nutraceuticals from plants. Trends in Food Science \& Technology, Vol. 17 (6), p. 300-312.

18. Yang B., Kallio H. (2002) Composition and physiological effects of sea buckthorn (Hippophaë) lipids, Trends in Food Science \& Technology, Vol.13(5), p. 160-167. 